\title{
Effect of the Length of Side Group Substitution on Optical and Electroluminescene Properties
}

\author{
Hwangyu Shin, Hyeonmi Kang, Beomjin Kim, Youngil Park, ${ }^{\dagger}$ Young-Jun Yu, ${ }^{\ddagger}$ and Jongwook Park* \\ Department of Chemistry, The Catholic University of Korea, Bucheon 420-743, Korea \\ *E-mail: hahapark@catholic.ac.kr,mabams@catholic.ac.kr \\ ${ }^{\dagger}$ Research Center for Green Fine Chemicals, Korea Research Institute of Chemical Technology, Ulsan 681-802, Korea \\ ${ }^{\star}$ LG display Co. Ltd, Paju-si, Gyeonggi 413-811, Korea \\ Received May 26, 2014, Accepted June 30, 2014
}

\begin{abstract}
Blue emitting materials, 9,10-bis-biphenyl-4-yl-anthracene (AC-P), 9,10-bis-[1,1';4',1"]terphenyl-4-yl-anthracene (AC-DP), and 9,10-bis[3",5"-deiphenyltriphenyl-4'-yl]anthracene (AC-TP) were synthesized through boration and Suzuki aryl-aryl coupling reaction. EL performance of blue light-emitters was optimized and improved by varying the chemical structures of the side groups. In the thin film state, the three materials exhibit $\mathrm{PL}_{\max }$ values in the range of $442-456 \mathrm{~nm}$. EL device with the synthesized compounds in the following configuration was fabricated: ITO/4,4',4"-tris( $N$-(2-naphthyl)- $N$-phenylamino)triphenylamine $\quad$ (2-TNATA) $60 \mathrm{~nm} / N, N^{\prime}$-bis (naphthalene-1-yl)- $N, N^{\prime}$-bis(phenyl)benzidine (NPB) $15 \mathrm{~nm} /$ synthesized blue emitting materials $(30 \mathrm{~nm}) / 1,3,5-$ tri(1-phenyl-1H-benzo[d]imidazol-2-yl)phenyl (TPBi) 20nm/LiF 1nm/Al 200nm. The current efficiency and C.I.E. value of AC-TP were $3.87 \mathrm{~cd} / \mathrm{A}$ and $(0.15,0.12)$. A bulky and non-planar side group helps to prevent $\pi-\pi^{*}$ stacking interaction, which should lead to the formation of more reliable amorphous film. This is expected to have a positive effect on the high efficiency of the operating OLED device.
\end{abstract}

Key Words : OLED, Blue emitter, Anthracene derivatives

\section{Introduction}

Intensive studies have been conducted on organic lightemitting diodes (OLEDs) as they have a great potential to be applied to large full-color displays and mobile displays. ${ }^{1-3}$ Most of the conjugated organic molecules have been reported as red, green and blue electroluminescence (EL). ${ }^{4}$ It is required for those red, green and blue emitters to show high EL efficiency, good thermal properties, long lifetime and pure color coordinates (1931 Commission Internationale de l'Eclairage (C.I.E.)), in order to be applied to large full-color displays. A red light-fluorescence emitter with C.I.E. coordinates of $(0.66,0.34)$ and a long lifetime of more than $600,000 \mathrm{~h}$ at $24 \mathrm{~cd} / \mathrm{A}$ has recently been developed. A green light-fluorecence emitter with C.I.E. coordinates of $(0.34$, 0.62 ) and a life time of $400,000 \mathrm{~h}$ at $78 \mathrm{~cd} / \mathrm{A}$ has also been achieved. However, the best official results for a blue-light emitter are a short lifetime of only $10,000 \mathrm{~h}$ at $9.0 \mathrm{~cd} / \mathrm{A}$ and C.I.E. coordinates of $(0.14,0.12)$ with fluorescence materials. Thus, the development of a blue emitter with high color purity, high efficiency and a long lifetime is an extremely challenging research topics. Most existing studies of blue emitters use molecules with excellent fluorescence characteristics such as anthracene, ${ }^{5,6}$ pyrene ${ }^{7,8}$ as core or side moieties. Many studies have investigated the use of anthracene and pyrene as blue core moiety since they have high photoluminescence (PL) and EL efficiencies. However, these molecules can easily form excimers through packing because anthracene and pyrene have flat molecular structure that reduce EL efficiency and degrade color purity. ${ }^{9}$
In this work, new blue emitting compounds based on anthracene which has high PL efficiency were designed and synthesized. Those compounds have different length and size of side group. Optical and electrical properties of these compounds were examined.

\section{Experimental}

\section{Synthetic Method.}

Synthesis of 9,10-Bis-(4-bromo-phenyl)-anthracene [1]: 1,4-Dibromo benzene $(2.27 \mathrm{~g}, 9.61 \mathrm{mmol})$ was dissolved in $50 \mathrm{~mL}$ of dry THF solution and stirred at $-78^{\circ} \mathrm{C}$, the $2.0 \mathrm{M}$ $n$-BuLi (6.4 mL) was added. Then anthraquinone (1.0 g, 4.8 $\mathrm{mmol}$ ) and water $200 \mathrm{~mL}$ were added to the reaction after 2 h. After the reaction was finished, extracted with diethyl ether and water. The organic layer was dried by evaporator. Which mixture was dissolved in acetic acid $40 \mathrm{~mL}$, was

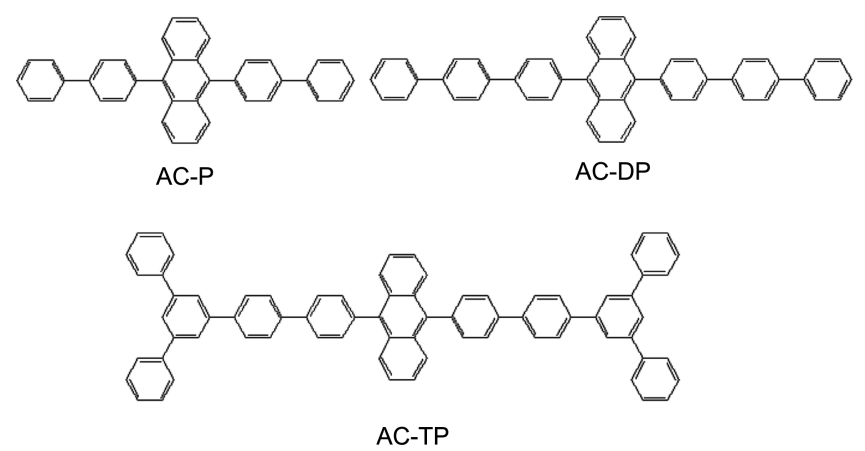

Figure 1. Chemical structures of synthesized compounds. 
added to the reaction mixture. Then $\mathrm{KI}$ and $\mathrm{NaHPO}_{2} \mathrm{H}_{2} \mathrm{O}$ were added to the reaction after $2 \mathrm{~h}$. After the reaction was finished, extracted with diethyl ether and water. The mixture was evaporated. The precipitate was filtered and washed excess methanol. The solvent was evaporated to give a compound $\mathbf{1}$ as white solid, which was recrystallized from dichloromethane $\left(\mathrm{CH}_{2} \mathrm{Cl}_{2}\right)$ and methanol (Yield $\left.89 \%\right) .{ }^{1} \mathrm{H}$ NMR $\left(300 \mathrm{MHz}, \mathrm{CDCl}_{3}\right) \delta 7.9(\mathrm{~d}, 4 \mathrm{H}), 7.6(\mathrm{~d}, 4 \mathrm{H}), 7.3$ (d, 4H), $7.2(\mathrm{~d}, 4 \mathrm{H})$.

Synthesis of 9,10-Bis-biphenyl-4-yl-anthracene[AC-P]: Compound 1 (1.0 g, $2.2 \mathrm{mmol})$, phenyl bronic acied (1.2 g, $5.6 \mathrm{mmol}), \mathrm{Pd}(\mathrm{OAc})_{2}$ and (cyclohexyl $)_{3} \mathrm{P}(0.07 \mathrm{~g})$ were added to toluene $(50 \mathrm{~mL})$ solution. Then tetraethylammonium hydroxide $(20 \mathrm{wt} \%, 8 \mathrm{~mL})$ was added to the reaction mixture. After the reaction was finished, extracted with diethyl ether and water. The organic layer was dried with anhydrous $\mathrm{MgSO}_{4}$ and filterd. The solvent was evaporated. The yellowish powder was purified by using column chromatography with $\mathrm{CHCl}_{3}$ : hexane (1:10) eluent to afford a beige solid (AC-P) (Yield 91\%). ${ }^{1} \mathrm{H}$ NMR (300 MHz, $\left.\mathrm{CDCl}_{3}\right) \delta 7.86(\mathrm{~d}, 4 \mathrm{H}), 7.80(\mathrm{~m}, 8 \mathrm{H}), 7.56(\mathrm{~d}, 4 \mathrm{H}), 7.53(\mathrm{~d}$, 4H), 7.42 (d, 2H), 7.36 (m, 4H). FAB-Mass: $482.20 \mathrm{~m} / \mathrm{z}$.

Synthesis of 4-Borolanebiphenyl [2]: 4-Bromobiphenyl $(5.0 \mathrm{~g}, 16.2 \mathrm{mmol})$ was dissolved in $100 \mathrm{~mL}$ of dry THF solution and stirred at $-78{ }^{\circ} \mathrm{C}$, the $2.0 \mathrm{M} n$-BuLi $(17 \mathrm{~mL})$ was added. Then isopropoxy-4,4,5,5-tetramethyl-1,3,2-dioxaborolane $(6.65 \mathrm{~mL})$ was added to the reaction mixture. After the reaction was finished, extracted with diethyl ether and water. The organic layer was dried by evaporator. Product was recrystallized from dichloromethane $\left(\mathrm{CH}_{2} \mathrm{Cl}_{2}\right)$ and methanol (Yield 91.5\%). ${ }^{1} \mathrm{H}$ NMR $\left(300 \mathrm{MHz}, \mathrm{CDCl}_{3}\right) \delta$ $7.7(\mathrm{~s}, 3 \mathrm{H}), 7.6(\mathrm{~d}, 4 \mathrm{H}), 7.45(\mathrm{t}, 4 \mathrm{H}), 7.4(\mathrm{t}, 2 \mathrm{H})$.

Synthesis of 9,10-Bis-[1,1';4',1"']terphenyl-4-yl-anthracene [AC-DP]: Compound 2 ( $0.2 \mathrm{~g}, 0.5 \mathrm{mmol})$, compound 1 $(0.17 \mathrm{~g}, 0.25 \mathrm{mmol}), \mathrm{Pd}(\mathrm{OAc})_{2}$ and (cyclohexyl $)_{3} \mathrm{P}(0.06 \mathrm{~g})$ were added to toluene $(30 \mathrm{~mL})$ solution. Then tetraethylammonium hydroxide ( $20 \mathrm{wt} \%, 1 \mathrm{~mL}$ ) was added to the reaction mixture. After the reaction was finished, extracted with diethyl ether and water. The organic layer was dried with anhydrous $\mathrm{MgSO}_{4}$ and filterd. The solvent was evaporated. The yellowish powder was purified by using column chromatography with $\mathrm{CHCl}_{3}$ :hexane (1:10) eluent to afford a beige solid (AC-DP) (Yield 68\%). ${ }^{1} \mathrm{H}$ NMR (300 MHz, $\left.\mathrm{CDCl}_{3}\right) \delta 8.04(\mathrm{~d}, 4 \mathrm{H}), 7.99(\mathrm{~d}, 4 \mathrm{H}), 7.88(\mathrm{~m}, 14 \mathrm{H}), 7.60(\mathrm{~m}$, $6 \mathrm{H}), 7.49$ (m, 6H). FAB-Mass: $634.27 \mathrm{~m} / \mathrm{z}$.

Synthesis of 1-Bromo-3,5-diphenylbenzene [3]: 1,3,5Tribromobenzene (20 g, $62 \mathrm{mmol}), \mathrm{Pd}\left(\mathrm{PPh}_{3}\right)_{4}(3.57 \mathrm{~g}, 3.1$ mmol) were added to $300 \mathrm{~mL}$ of dry THF solution, then phenylbronic acid (32 g, $155 \mathrm{mmol})$ and $2 \mathrm{M} \mathrm{K}_{2} \mathrm{CO}_{3}$ solution $(50 \mathrm{~mL})$, which was dissolved in $\mathrm{H}_{2} \mathrm{O}$, was added to the reaction mixture. The reaction mixture was heated to 65 ${ }^{\circ} \mathrm{C}$ for $5 \mathrm{~h}$ under nitrogen. After the reaction was finished, extracted with diethyl ether and water. The organic layer was dried with anhydrous $\mathrm{MgSO}_{4}$ and filterd. The solvent was evaporated. The product was isolated by silica gel column chromatography using $\mathrm{CHCl}_{3}$ :hexane (1:15) eluent to afford a white solid (Yield 61\%). ${ }^{1} \mathrm{H}$ NMR $\left(300 \mathrm{MHz}, \mathrm{CDCl}_{3}\right) \delta 7.7$ (s, 3H), $7.6(\mathrm{~d}, 4 \mathrm{H}), 7.45(\mathrm{t}, 4 \mathrm{H}), 7.4(\mathrm{t}, 2 \mathrm{H})$.

Synthesis of 1-Borolane-3,5-diphenylbenzene [4]: Compound 3 ( $6.0 \mathrm{~g}, 38.7 \mathrm{mmol})$ was dissolved in $100 \mathrm{~mL}$ of anhydrous THF solution and stirred at $-78^{\circ} \mathrm{C}$, the $2.0 \mathrm{M} \mathrm{n}$ $\mathrm{BuLi}$ (12.4 mL) was added. Then isopropoxy-4,4,5,5tetramethyl-1,3,2-dioxaborolane $(4 \mathrm{~mL})$ was added to the reaction mixture. After the reaction was finished, extracted with diethyl ether and water. The organic layer was dried by evaporator. Which product was recrystallized from dichloromethane $\left(\mathrm{CHCl}_{3}\right)$ and methanol (Yield 86.9\%). ${ }^{1} \mathrm{H}$ NMR $\left(300 \mathrm{MHz}, \mathrm{CDCl}_{3}\right) \delta 7.71(\mathrm{~s}, 3 \mathrm{H}), 7.62(\mathrm{~d}, 4 \mathrm{H}), 7.46(\mathrm{t}, 4 \mathrm{H})$, $7.40(\mathrm{t}, 2 \mathrm{H}), 1.37(\mathrm{~s}, 12 \mathrm{H})$.

Synthesis of 4-(4-Bromophenyl)-2,6-diphenylbenzene [5]: Compound 4 (2.5 g, $7.0 \mathrm{mmol}), \mathrm{Pd}\left(\mathrm{PPh}_{3}\right)_{4}(0.45 \mathrm{~g}, 0.35$ mmol) were added to $100 \mathrm{~mL}$ of dry THF solution, then 1,4dibromobenzene $(9.6 \mathrm{~g}, 15 \mathrm{mmol})$ and $2 \mathrm{M} \mathrm{K}_{2} \mathrm{CO}_{3}$ solution $(7 \mathrm{~mL})$, which was dissolved in $\mathrm{H}_{2} \mathrm{O}$, was added to the reaction mixture. The reaction mixture was heated to $65^{\circ} \mathrm{C}$ for $3 \mathrm{~h}$ under nitrogen. After the reaction was finished, extracted with diethyl ether and water. The organic layer was dried with anhydrous $\mathrm{MgSO}_{4}$ and filterd. The solvent was evaporated. The product was isolated by silica gel column chromatography using $\mathrm{CHCl}_{3}$ :hexane (1:10) eluent to afford a white solid (Yield 77\%). ${ }^{1} \mathrm{H}$ NMR $\left(300 \mathrm{MHz}, \mathrm{CDCl}_{3}\right) \delta$ $7.80(\mathrm{~s}, 1 \mathrm{H}), 7.74(\mathrm{~s}, 2 \mathrm{H}), 7.69(\mathrm{~d}, 4 \mathrm{H}), 7.58(\mathrm{~m}, 4 \mathrm{H}), 7.48(\mathrm{t}$, $4 \mathrm{H}), 7.39(\mathrm{t}, 2 \mathrm{H})$.

Synthesis of 4-(4-Borolanephenyl)-2,6-diphenylbenzene [6]: Compound 5 (4.0 g, $7.8 \mathrm{mmol}$ ) was dissolved in $60 \mathrm{~mL}$ of anhydrous THF solution and stirred at $-78^{\circ} \mathrm{C}$, the $2.0 \mathrm{M}$ $n$-BuLi $(6.2 \mathrm{~mL})$ was added. Then isopropoxy-4,4,5,5tetramethyl-1,3,2-dioxaborolane $(2.44 \mathrm{~mL})$ was added to the reaction mixture. After the reaction was finished, extracted with diethyl ether and water. The organic layer was dried by evaporator. Which product was recrystallized from dichloromethane $\left(\mathrm{CHCl}_{3}\right)$ and methanol (Yield 71.9\%). ${ }^{1} \mathrm{H}$ NMR $\left(300 \mathrm{MHz}, \mathrm{CDCl}_{3}\right) \delta 7.93(\mathrm{~s}, 1 \mathrm{H}), 7.80(\mathrm{~s}, 2 \mathrm{H}), 7.71(\mathrm{~d}, 4 \mathrm{H})$, $7.69(\mathrm{~m}, 4 \mathrm{H}), 7.39$ (t, 4H), 7.39 (t, 2H) 1.35 (s, 12H).

Synthesis of 9,10-Bis[3",5"'-diphenyltriphenyl-4'-yl] anthracene [AC-TP]: Compound 6 (2.0 g, $4.6 \mathrm{mmol})$, $\mathrm{Pd}\left(\mathrm{PPh}_{3}\right)_{4}(0.31 \mathrm{~g}, 0.14 \mathrm{mmol})$ were added to $50 \mathrm{~mL}$ of dry toluene solution, then compound $1(2.1 \mathrm{~g}, 2.3 \mathrm{mmol})$ and 2 $\mathrm{M} \mathrm{K}_{2} \mathrm{CO}_{3}$ solution $(10 \mathrm{~mL})$, which was dissolved in $\mathrm{H}_{2} \mathrm{O}$, was added to the reaction mixture. The reaction mixture was heated to $85^{\circ} \mathrm{C}$ for $3 \mathrm{~h}$ under nitrogen. After the reaction was finished, extracted with diethyl ether and water. The organic layer was dried with anhydrous $\mathrm{MgSO}_{4}$ and filterd. The solvent was evaporated. The product was isolated by silica gel column chromatography using $\mathrm{CHCl}_{3}$ :hexane (1:4) eluent to afford a white solid (Yield 57\%). ${ }^{1} \mathrm{H}$ NMR (300 $\left.\mathrm{MHz}, \mathrm{CDCl}_{3}\right) \delta 7.95(\mathrm{~s}, 2 \mathrm{H}), 7.90(\mathrm{~m}, 12 \mathrm{H}), 7.83(\mathrm{~m}, 8 \mathrm{H})$, $7.75(\mathrm{~d}, 8 \mathrm{H}), 7.60$ (d, 4H), $7.51(\mathrm{t}, 8 \mathrm{H}), 7.40$ (m, 8H). FABMass: $939.39 \mathrm{~m} / \mathrm{z}$.

Measurements. Reagents and solvents were purchased as reagent grade and used without further purification. All reactions were performed using dry glassware under nitrogen atmosphere. Analytical TLC was carried out on Merck 60 F254 silica gel plate and column chromatography was 

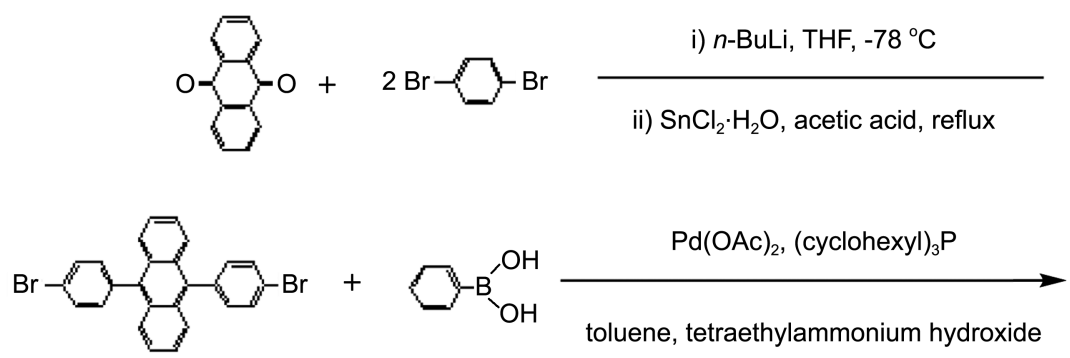

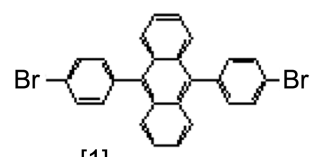

[1]

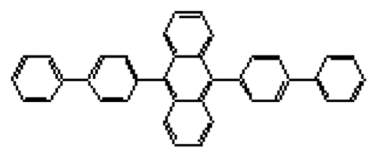

AC-P

[1]

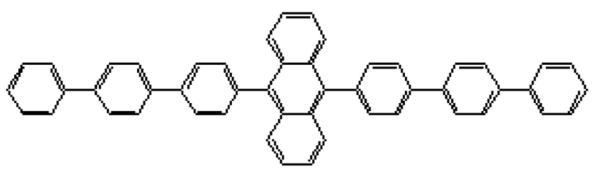

AC-DP

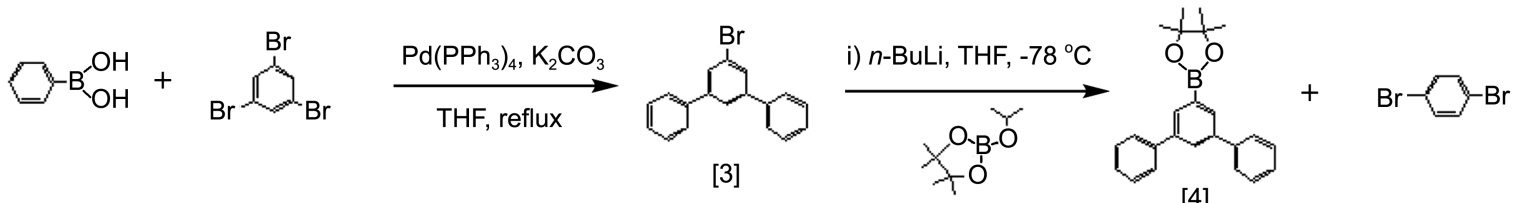

[3]

[4]

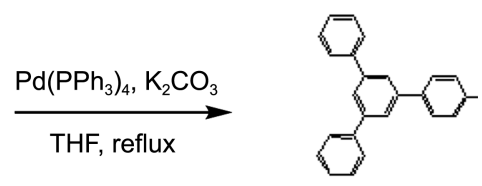

[5]
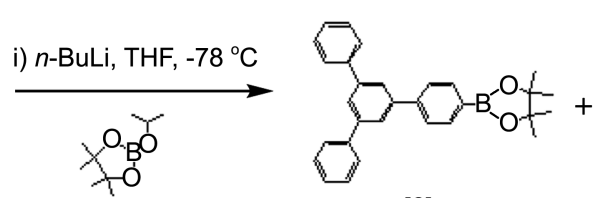

[6]
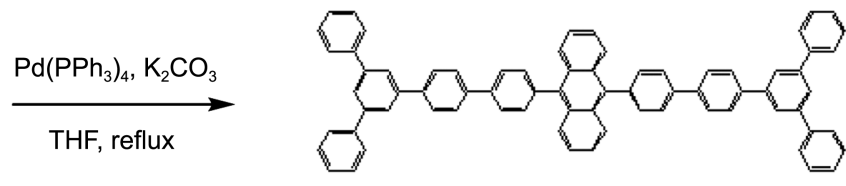

AC-TP

Figure 2. Synthetic routes of synthesized compounds.

performed on Merck 60 silica gel (230-400 mesh). Melting points were determined on an Electrothemal IA 9000 series melting point apparatus and are uncorrected. ${ }^{1} \mathrm{H}-\mathrm{NMR}$ spectra were recorded on Bruker, Advance 300 spectrometer with TMS peak as reference. The optical absorption spectra were obtained by HP 8453 UV-VIS-NIR spectrometer. Thermal properties of the compounds were measured by thermogravimetric analysis (TGA) and differential scanning calorimeter (DSC) using a SDT2960 and DSC2910 (TA Instruments). Voyager-DE-STR, elemental analysis was performed with a Perkin-Elmer 2400 analyzer. Perkin Elmer luminescence spectrometer LS50 (Xenon flash tube) was used for PL spectroscopy. Surface analyzer AC-2 (RIKEN KEIKI) was used for work function measurement. EL devices were fabricated as the following structure: ITO/2TNATA $60 \mathrm{~nm} / \mathrm{NPB} 15 \mathrm{~nm} / \mathrm{EML} 30 \mathrm{~nm} / \mathrm{TPBi} 20 \mathrm{~nm} / \mathrm{LiF} 1 \mathrm{~nm}$ /Al 200nm, where 4,4',4"-tris( $N$-(2-naphthyl)- $N$-phenylamino)-triphenylamine (2-TNATA) was used as a hole injection layer (HIL), $N, N^{\prime}$-bis(naphthalene-1-ly)- $N, N^{\prime}$-bis(phenyl)benzidine (NPB) as a hole transporting layer (HTL), the synthesized materials as emitting layer (EML), 1,3,5-tri(1phenyl-1H-benzo[d]imidazol-2-yl)phenyl (TPBi) as an 

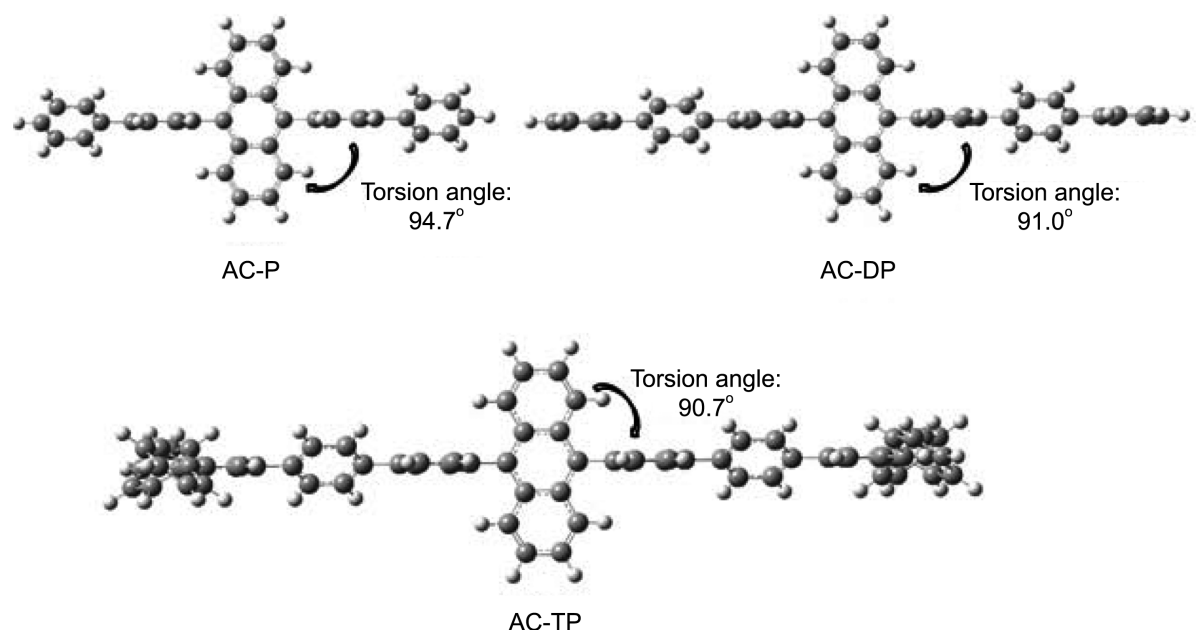

Figure 3. Optimized molecular structures of synthesized compounds.

electron transporting layer (ETL) and hole blocking layer (HBL), lithium fluoride (LiF) as an electron injection layer (EIL), ITO as anode and $\mathrm{Al}$ as cathode. The organic layer was vacuum deposited by using thermal evaporation at a vacuum base pressure of $10^{-6}$ torr and the rate of deposition being $1 \AA / S$ to give an emitting area of $4 \mathrm{~mm}^{2}$ and the $\mathrm{Al}$ layer was continuously deposited under the same vacuum condition. The current-voltage-luminance (I-V-L) characteristics of the fabricated EL devices were obtained by Keithley 2400 electrometer and light intensity was obtained by Minolta CS 1000A.

\section{Results and Discussion}

The synthesized compounds are shown in Figure 1 and the optical properties of synthesized compounds were summarized in Table 1. In Figure 3, the torsion angles of three compounds between the anthracene core and the side group are shown to be very similar: $94.7,91.0$ and $90.7^{\circ}$, respectively. Figure 4 shows UV-visible (UV-Vis.) absorption and PL spectra data in solution state. Figure 4 also exhibits spectra data in film state. Solvent was used with chloroform $\left(1 \times 10^{-5} \mathrm{M}\right)$ in solution case and $50 \mathrm{~nm}$ thickness was chosen for evaporated film on glass. In Figure 4 and Table 1, AC-P, AC-DP and AC-TP show maximum absorption values at $359,377,398 \mathrm{~nm}$, respectively. These three peak values came from vibronic absorption peaks and it is a typical anthracene absorption peak. AC-P exhibits $\mathrm{PL}_{\max }$ at $431 \mathrm{~nm}$. AC-DP and AC-TP show PL $\mathrm{max}_{\text {ax }}$ at 433 and $437 \mathrm{~nm}$,

Table 1. Optical properties of synthesized compounds

\begin{tabular}{ccccc}
\hline \multirow{2}{*}{ Compound } & Solution $^{a}$ & Film $^{b}$ & Solution $^{a}$ & Film $^{b}$ \\
\cline { 2 - 5 } & $\mathrm{UV}_{\max }(\mathrm{nm})$ & $\mathrm{UV}_{\max }(\mathrm{nm})$ & $\mathrm{PL}_{\max }(\mathrm{nm})$ & $\mathrm{PL}_{\max }(\mathrm{nm})$ \\
\hline AC-P & $359,377,398$ & $358,377,398$ & 431 & 435 \\
AC-DP & $359,377,397$ & $363,382,403$ & 433 & 445 \\
AC-TP & $360,378,398$ & $365,384,404$ & 437 & 448 \\
\hline
\end{tabular}

${ }^{a} 10^{-5} \mathrm{M}$ in chloroform. ${ }^{b}$ film thickness of $50 \mathrm{~nm}$

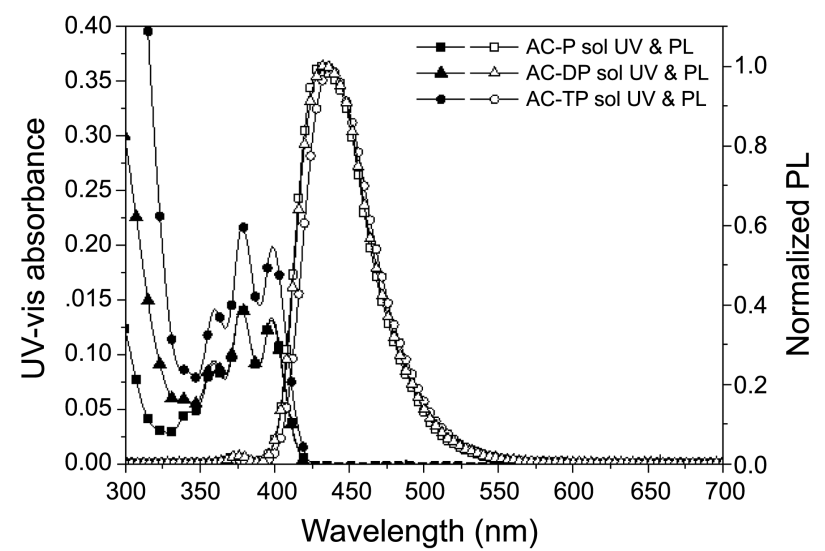

Figure 4. UV-Vis. absorption and PL spectra of AC-P ( $\square)$, AC-DP $(\triangle)$, AC-TP $(\mathrm{O})$ in $\mathrm{CHCl}_{3}$ solution $\left(1 \times 10^{-5} \mathrm{M}\right)$

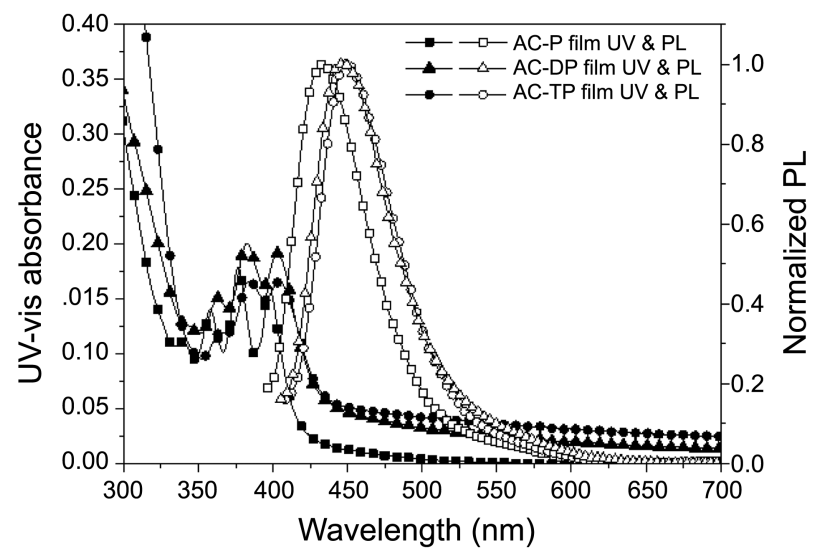

Figure 5. UV-Vis. absorption and PL spectra of AC-P ( $\square$ ), AC$\mathrm{DP}(\triangle)$, AC-TP $(\mathrm{O})$ in film state (thickness is $50 \mathrm{~nm}$ ).

which means deep blue.

As shown in Figure 5 and Table 1, AC-P film showed maximum absorption value at $358,377,398 \mathrm{~nm}$ as well as $\mathrm{PL}_{\max }$ value at $434 \mathrm{~nm}$. In AC-DP and AC-TP cases, two compounds showed similar absorption maximum values at 363,382 and $403 \mathrm{~nm}, \mathrm{PL}_{\max }$ values were slightly different as 
Table 2. Energy level of synthesized compounds

\begin{tabular}{cccc}
\hline Compound & $\begin{array}{c}\text { HOMO } \\
(\mathrm{eV})\end{array}$ & $\begin{array}{c}\text { LUMO } \\
(\mathrm{eV})\end{array}$ & $\begin{array}{c}\text { Band } \\
\text { gap }\end{array}$ \\
\hline AC-P & -5.86 & -2.89 & 2.97 \\
AC-DP & -5.76 & -2.87 & 2.89 \\
AC-TP & -5.74 & -2.86 & 2.88 \\
\hline
\end{tabular}

\section{5 and $448 \mathrm{~nm}$.}

AC-DP and AC-TP had absorption and $\mathrm{PL}_{\max }$ values slightly red shifted in film state compared to AC-P. This is a phenomenon that appears with increase in conjugation length due to addition of a phenyl unit in para position to the side group of AC-P. ${ }^{10}$ As shown in Figure 1, AC-P has two sequential phenyl groups at side position and AC-DP and AC-TP have three phenyl rings. Since AC-DP and AC-TP have similar conjugation length based on three phenyl rings at side group, absorption and $\mathrm{PL}_{\max }$ values were also shown to be similar.

Energy levels of three synthesized compounds such as HOMO, LUMO, and band gap were estimated by ultraviolet photon spectroscopy of AC-2 and optical absorption spectroscopy (see Table 2). AC-P had HOMO and band gap values of $-5.86 \mathrm{eV}$ and $2.97 \mathrm{eV}$. AC-DP and AC-TP showed HOMO values of $-5.76 \mathrm{eV}$ and $-5.74 \mathrm{eV}$, and band gap values of $2.89 \mathrm{eV}$ and $2.88 \mathrm{eV}$, respectively (Table 2). Band gap was slightly decreased and emission wavelength was red-shifted according to the change from AC-P to AC-DP and AC-TP. However, there was no remarkable change of optical property according to the change from AC-DP to AC-TP. It can be explained by that two phenyl rings at meta position in $\mathrm{AC}$-TP is not effective to change the conjugation length of side group.

OLED devices of three compounds as an emitting layer (EML) were fabricated as ITO/2-TNATA $60 \mathrm{~nm} / \mathrm{NPB} 15 \mathrm{~nm} /$ EML 30nm/TPBi 20nm/LiF 1nm/Al 200nm. All organic films were prepared by evaporation under high vacuum of $10^{-6}$ torr.

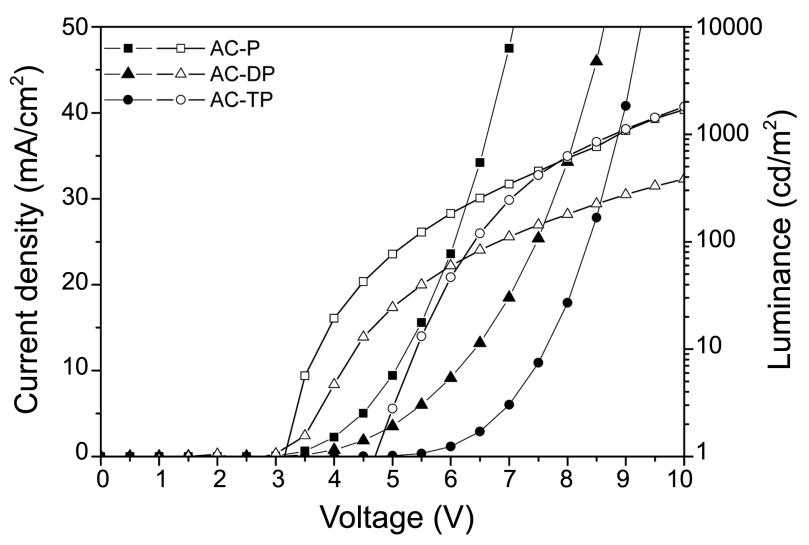

Figure 6. I-V-L graphs of AC-P, AC-DP, AC-TP OLED devices. Filled symbols: Current density, empty symbols: Luminance. (Device: 2-TNATA (60nm)/ NPB (15nm)/ EML (30nm)/ TPBi (20nm)/ LiF (1nm)/ Al (200nm))

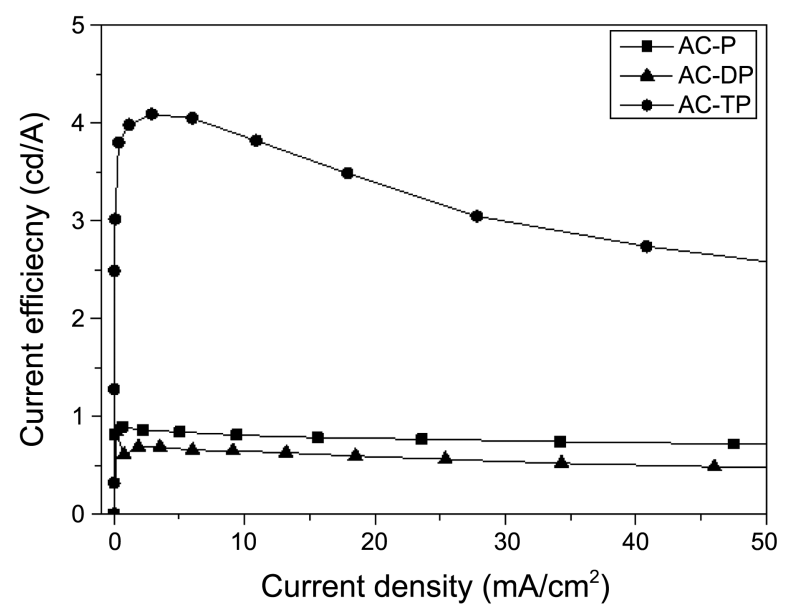

Figure 7. Current efficiency of AC-P, AC-DP, AC-TP OLED devices. (Device: 2-TNATA (60nm)/ NPB (15nm)/ EML (30nm)/ TPBi (20nm)/ LiF (1nm)/ Al (200nm)).

Table 3. EL performance of multilayered devices with the synthesized compounds at $10 \mathrm{~mA} / \mathrm{cm}^{2}$

\begin{tabular}{cccccccc}
\hline Device & $\begin{array}{c}\text { Volt } \\
(\mathrm{V})\end{array}$ & $\begin{array}{c}\text { C.E. } \\
(\mathrm{cd} / \mathrm{A})\end{array}$ & $\begin{array}{c}\text { P.E. } \\
(\mathrm{lm} / \mathrm{W})\end{array}$ & $\begin{array}{c}\text { E.Q.E. } \\
(\%)\end{array}$ & $\begin{array}{c}\text { C.I.E. } \\
(\mathrm{x}, \mathrm{y})\end{array}$ & $\begin{array}{c}\text { EL } \\
(\mathrm{nm})\end{array}$ & $\begin{array}{c}\text { FWHM } \\
(\mathrm{EL}) \\
(\mathrm{nm})\end{array}$ \\
\hline AC-P & 5.10 & 0.80 & 0.55 & 0.76 & $0.17,0.17$ & 457 & 72 \\
AC-DP & 6.10 & 0.65 & 0.47 & 0.47 & $0.19,0.21$ & 441 & 82 \\
AC-TP & 7.38 & 3.87 & 1.81 & 4.50 & $0.15,0.12$ & 451 & 53 \\
\hline
\end{tabular}

Device: ITO/ 2-TNATA 60nm/ NPB 15nm/ EML 35nm/ TPBi 20nm/ $\mathrm{LiF} 1 \mathrm{~nm} / \mathrm{Al} 200 \mathrm{~nm}$

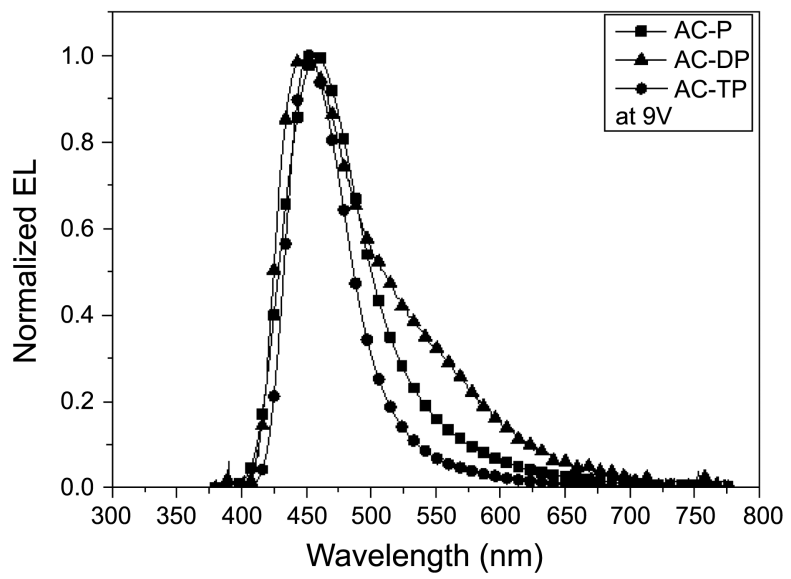

Figure 8. EL spectra of AC-P, AC-DP, AC-TP OLED devices. (Device: 2-TNATA (60nm)/ NPB (15nm)/ EML (30nm)/ TPBi (20 $\mathrm{nm}) / \mathrm{LiF}(1 \mathrm{~nm}) / \mathrm{Al}(200 \mathrm{~nm}))$.

Figure 6 shows I-V-L characteristics of three devices. ${ }^{12,13}$ It exhibits current density and luminance according to the applied voltage. Three compounds showed typical I-V-L characteristics and AC-P exhibited the lowest operating voltage compared to two compounds devices. However, ACTP had superior luminance property to other two compounds. The related values were summarized in Table 3 .

While AC-P and AC-DP showed low current efficiency of 
0.80 and $0.65 \mathrm{~cd} / \mathrm{A}$ and external quantum efficiency (E.Q.E.) of 0.76 and $0.47 \%$, AC-TP showed $3.87 \mathrm{~cd} / \mathrm{A}$ and E.Q.E. of $4.5 \%$. With introduction of 1,3,5-triphenylbenzene as the bulky side group, efficiency was improved 5 times. Furthermore, narrow EL peak of AC-TP having deep blue emission of $(0.15,0.12)$ was shown compared to AC-P and AC-DP although AC-TP had relatively longer $\mathrm{PL}_{\max }$ wavelength.

Figure 8 shows EL spectra of three compounds devices at 9.0 voltage. Full width at half maximums (FWHM) of AC-P, AC-DP, and AC-TP were 72, 82, and 53.

The reason for AC-TP to have high EL efficiency among molecules with the same anthracene core is that absolute PL quantum efficiency $(0.29)^{14}$ of triphenyl benzene group has higher efficiency than that $(0.06)$ of the phenyl side group.

As a result of verifying optical and electrical properties according to the change of the side group, wavelength was shifted with the increase in conjugation length as the aromatic side group was substituted in para position. In addition, color purity was improved and the EL efficiency was greatly increased by decrease in intermolecular interaction with substitution of the bulky side group.

\section{Conclusion}

Three anthracene derivatives with EL luminescence properties that were fine-tuned by varying the bulky side group were synthesized. It was found out that bulky side group of triphenyl benzene increased EL efficiency compared to linear side group. AC-TP compound showed high EL efficiency of $3.87 \mathrm{~cd} / \mathrm{A}$ and $4.5 \%$ and $\mathrm{CIE}$ value was $(0.15,0.12)$ which means deep blue.

Acknowledgments. This work was supported by the National Research Foundation of Korea (NRF) grant funded by the Korea government (MEST) (No. 2012001846).

\section{References}

1. Tang, C. W.; Vanslyke, S. A. Appl. Phys. Lett. 1987, 51, 913.

2. Kim, J. S.; Heo, J.; Kang, P.; Kim, J. H.; Jung, S. O.; Kwon, S. K. Macromol. Res. 2009, 17, 91.

3. Park, H. T.; Shin, D. C.; Shin, S. C.; Kim, J. H.; Kwon, S. K.; Kim, Y. H. Macromol. Res. 2011, 19, 965.

4. Kim, S. K.; Park, Y. I.; Kang, I. N.; Lee, J. H.; Park, J. W. J. Mater. Chem. 2007, 17, 4670.

5. Lyu, Y.-Y..; Kwak, J. H.; Kwon, O. H.; Lee, S.-H.; Kim, D. Y.; Lee, C. H.; Char, K. H. Adv. Mater. 2008, 20, 2720.

6. Park, H. T.; Lee, J. H.; Kang, I.; Chu, H. Y.; Lee, J.-I.; Kwon, S.K.; Kim, Y.-H. J. Mater. Chem. 2013, 22, 2695.

7. Tao, S.; Jiang, Y.; Lai, S.-L.; Fung, M.-K.; Zhou, Y.; Zhang, X.; Zhao, W.; Lee, C.-S. Organic Electronics 2011, 12, 358.

8. Figueira-Duarte, T. M.; Rosso, P. G. D.; Trattnig, R.; Sax, S.; List, E. J. W.; Mullen, K. Adv. Mater. 2010, 22, 990.

9. Balaganesan, B.; Shen, W. J.; Chem, C. H. Tetrahedron Lett. 2003, 44, 5747.

10. Sonntag, M.; Strohriegl, P. Chem. Mater. 2004, 46, 3245.

11. Shin, P. I.; Chuang, C. Y.; Chien, C. H.; Diau, E. W. G.; Shu, C. F. Adv. Funct. Mater. 2007, 17, 3141.

12. Song, K. W.; Choi, M. H.; Han, M. H. Journal of Industrial Engineering Chemistry 2014, 20, 426.

13. Rashad, M. M.; Shalan, A. E.; Lira-Cantu, M. Journal of Industrial Engineering Chemistry 2013, 19, 2052.

14. Berlman, B. I. Handbook of Fluorescence Spectra of Aromatic Molecules; Academic Press: New York, 1971; vol. 2, p 473. 